\title{
Tecno-estética e formação: \\ especulações iniciais a partir de Simondon e Buckminster-Fuller
}

\section{Emerson Freire}

Faculdade de Tecnologia de Jundiaí

\section{Resumo}

Dois pensadores, cada qual à sua maneira, incorporaram sempre em suas reflexões a técnica enquanto componente primordial de seus trabalhos: o inventor norte-americano Richard Buckminster Fuller e o filósofo francês Gilbert Simondon. Ambos têm ressonâncias na forma de pensar a tecnologia em relação ao social e na maneira de conceber o processo inventivo. Técnica e estética não estão em contraposição ou separadas para ambos, muito menos são componentes hierarquicamente inferiores do conhecimento. O presente artigo procura explorar um pouco dessas ressonâncias, relacionando a noção de tecno-estética em Simondon à formação, de modo a contribuir para as questões colocadas pela sociedade atual.

Palavras-chave: Tecno-estética; invenção; formação.

\section{Résumé}

Deux penseurs, chacun à leur manière, ont toujours intégré la technique dans leur réflexions, tandis que composante primordiale de leurs oeuvres : l'inventeur Buckminster Fuller et le philosophe Gilbert Simondon. Les deux ont des résonances dans leur manière de penser la technologie par rapport au social et dans leur façon de concevoir le processus inventif. Technique et esthétique ne sont pas en opposition ou séparées, beaucoup moins de composants hiérarchiquement inférieurs de la connaissance. Cet article vise à explorer ces résonances et à mettre en rapport la notion de techno-esthétique chez Simondon à la formation, afin de contribuer aux questions posées par la société actuelle.

Mots-clés: Techno-estéthique, invention, formation.

\begin{tabular}{c}
\hline \hline Filosofia e Educação - ISSN 1984-9605 \\
Volume 6, Número 3 - Outubro de 2014
\end{tabular}


Um menino vem correndo, e pergunta: $\quad$ Nascido da mistura milagrosa de

"O que exatamente é o oceano?

matéria e energia, o oceano é um lugar

"O que é o mar?"

antigo.

Poderíamos dar a ele muitas estatísticas

Mas ele é mais que um mero lugar.

e nomes latinos.

No sentido literal, o oceano está vivo.

Mas a resposta não é algo que

encontramos num livro.

De fato, ele já estava repleto de vida

Para realmente entendermos o que é o

bilhões de anos antes dos ancestrais do

oceano, temos de vê-lo por nós mesmos.

Temos de ouvi-lo e saboreá-lo.

límulo arrastarem-se pela primeira vez

Temos de sentir o seu poder.

até a praia.

Todos os tipos de seres vieram

Para realmente compreendermos $o$

posteriormente, olhando rumo ao céu

oceano,

com olhos pré-históricos.

temos de vivê-lo.

O oceano é vasto, e a maioria de nós

Então, no espaço de uma vida, enquanto

só irá vivenciar apenas uma pequena

parte dele.

a humanidade alcançava as estrelas,

parece que toda a natureza entrou em

desequilibrio.

Uma perspectiva, como a de uma

iguana marinha deslizando pela água ao

largo da costa das Ilhas Galápagos.

(Oceanos, 2009. Filme de Jacques Perrin e Jacques Cluzaud)

alavras iniciais do filme Oceanos de Perrin e Cluzaud que, apesar
de substanciais, só ganham maior potência quando as imagens
seguintes são apresentadas (Figura 1 - sentido horário) e que ajudam a enunciar e fundamentar o que virá nesse artigo. 

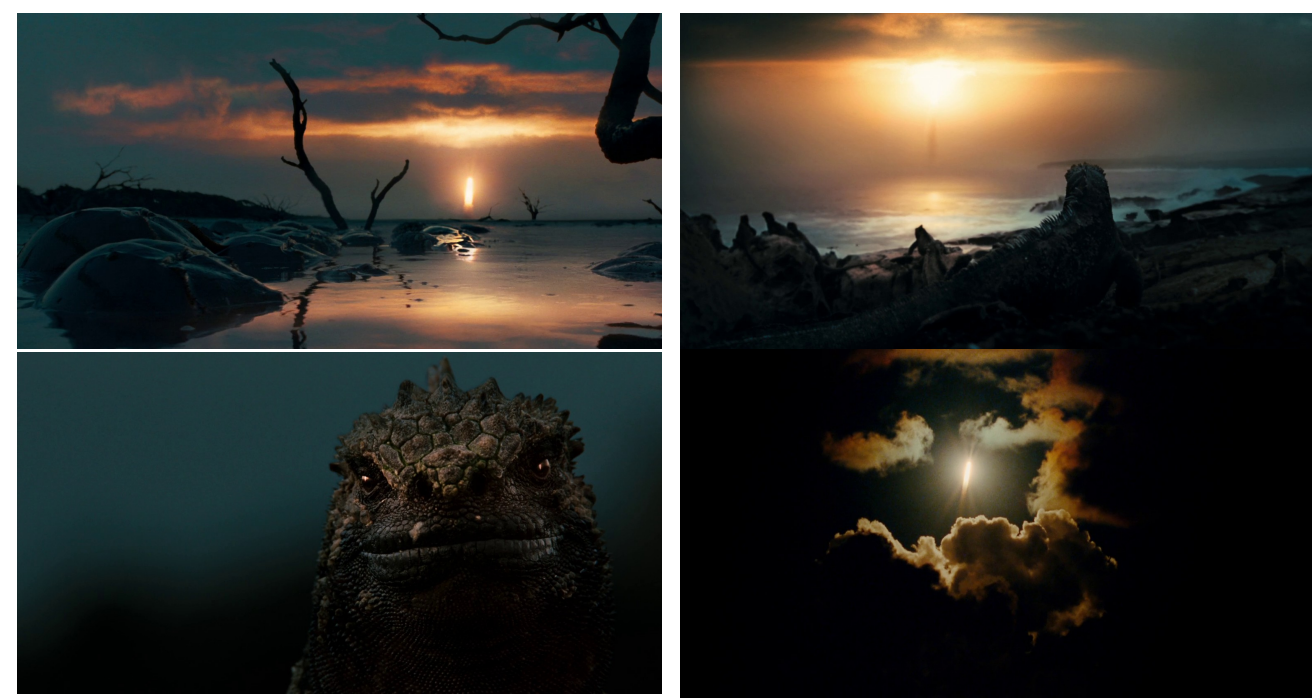

Figura 1 - Fotogramas de "Oceanos" (2009)

O foguete continua a subir aos céus e, sob olhar atento da iguana, mistura-se às estrelas da galáxia, um pequeno ponto em meio a imensidão do cosmos. Em seguida, bilhões de estrelas transformam-se em uma infinidade de pequenas gotas d'água no escuro do oceano, microscopicamente vistas, outra imensidão se impõe.

Perrin e Cluzaud fogem aos clichés à National Geographic, propondo uma conexão inusitada entre desenvolvimento tecno-científico acelerado e o primitivo, entre tecnologia-oceano-homem-cosmos. Límulos, iguanas, satélites, foguetes, homem, micro e macrocosmos, fazem parte de um movimento, compõem a imagem contemporânea, com as consequências ambientais que se observam dia-a-dia. Vale lembrar que tais imagens no filme são em Full HD (High Definition) e a tecnologia de captação dos sons e das imagens é das mais sofisticadas. Portanto, se por um lado não se trata de um esteticismo da natureza, por outro, também não é uma denúncia ecológica vulgar contrária ao desenvolvimento tecnológico, mas trata-se da constatação de que tal desenvolvimento tem raízes e efeitos mais profundos. Técnica e estética não estão em contraposição, mas compõem um conjunto para pensar tal movimento, do qual também fazem parte.

\begin{tabular}{c}
\hline \hline Filosofia e Educação - ISSN 1984-9605 \\
Volume 6, Número 3 - Outubro de 2014
\end{tabular}


É interessante observar que uma das grandes mentes do século XX, o inventor Richard Buckminster Fuller, ao escrever seu livro Critical Path (Fuller, 1981), também acentua que a profunda crise na qual a humanidade está mergulhada pode fazer parte de um processo cósmico. E não há nada de metafórico, ou mesmo de místico, nisso tudo. Aliás, os povos indígenas, muitas vezes chamados de primitivos pejorativamente, o sabem bem há muito tempo (Kopenawa \& Albert, 2010) ${ }^{1}$. Para Buckminster Fuller é como se a humanidade estivesse diante de um "exame final" cósmico e, por isso mesmo, ainda teria uma oportunidade de superar a crise e dar uma resposta satisfatória à sua sobrevivência. O curioso é que, após considerar o dispêndio de energia humano para sair dessa crise, Fuller diz que "isso somente pode ser realizado, entretanto, por meio de uma iniciativa de design da ciência e uma revolução tecnológica" (Fuller, 1981, p. xviii, trad. livre).

Todavia, é preciso um pouco de prudência nesse ponto. O Critical Path de Fuller está mais ligado à esperança do que a um otimismo exacerbado na tecnologia, como pode parecer de início. Por isso, ele salienta que se trata de uma espécie de função cósmica para a humanidade, para sua sobrevivência, dar uma resposta via tecnologia, uma maneira de modular o destino humano por meio da experiência tecnológica, mas, observa ele com veemência, desde que com integridade. E quando fala de integridade, Fuller já adianta: "Não estamos falando de lealdade para com sua mãe, seus amigos, seu colega de faculdade, ou seu chefe, que lhe dizem como se comportar ou pensar" (Fuller, 1981, p. Xxxvii, trad. livre).

Integridade está ligada à experiência direta do processo tecnológico, mais ainda, à invenção propriamente dita, ao entusiasmo individual, o que não significa solitário, no ato criativo para toda a humanidade como um princípio. Há uma grande distância de qualquer utopia tecnológica vista num sentido negativo. É sim um posicionamento político diante da

\footnotetext{
${ }^{1}$ Ver também a esse respeito SENRA (2011). 
aceleração da aceleração tecnológica. Em outras palavras, Fuller propõe en passant uma relação entre invenção e sobrevivência, algo vital. Por isso, vale salientar, que primeiro Fuller segue os passos de Marx e faz uma diferenciação entre dinheiro e riqueza, de certa forma, já desvinculando o ato criativo da geração imediata de dinheiro:

Aqueles que fazem dinheiro com dinheiro deliberadamente, o mantém escasso. Dinheiro não é riqueza. Riqueza é a capacidade tecnológica realizada para proteger, nutrir, apoiar e atender todas as crescentes necessidades da vida. Dinheiro é apenas um meio conveniente adotado de intercambiar itens de diferentes portes e não equacionáveis da riqueza real (Fuller, 1981, p. Xxvi, trad. livre).

Em seguida, ele faz um breve apanhado histórico, desde os fenícios às grandes navegações, passando por autores como Malthus, Darwin e o próprio Marx, para afirmar que a guerra é obsoleta, e que é preciso um esforço para converter a alta tecnologia de armamento para "livingry" (p. xxv). Livingry, neologismo de Fuller, tem como essência focar a alta tecnologia na vida-humana e no controle ambiental.

Buckminster Fuller desenvolve seu pensamento a partir da experiência da Apollo 11 e de todo um capítulo dedicado ao oceano, quando define os terráqueos como tecnologias projetadas hidraulicamente, fixando a água como fator vital. O interessante a observar é essa articulação entre invenção e o movimento da natureza. Na verdade, não há separação, a invenção surge, ou melhor ainda, faz parte do desenvolvimento cósmico atuando na Terra.

É todo esse o mote do trabalho de Buckminster Fuller enquanto arquiteto, engenheiro, geômetra, cartógrafo, filósofo, futurólogo, embora mais conhecido como o inventor do famoso domo geodésico.

\begin{tabular}{c}
\hline \hline Filosofia e Educação - ISSN 1984-9605 \\
Volume 6, Número 3 - Outubro de 2014
\end{tabular}


A obra de outro pensador, nem um pouco menos inventor, o filósofo francês Gilbert Simondon, permite ressonâncias fundamentais às práticas de Buckminster-Fuller. Essas ressonâncias, que são a base desse artigo, merecem serem aprofundadas principalmente no que concerne às discussões sobre invenção, educação, tecnologia e estética.

Simondon escreve uma frase surpreendente em um de seus artigos que reflete sobre a técnica na sociedade:

\section{A técnica é ainda mais primitiva que a religião, ela reúne a elaboração e a satisfação de necessidades biológicas em si mesmas; ela pode, portanto, intervir como elo formando conjuntos entre homens de grupos diferentes, ou entre os homens e o mundo, em circunstâncias bem menos estreitamente limitadas que aquelas que autorizam a plena utilização da linguagem ou a plena comunicação religiosa (Simondon, 1990, p. 10, destaque nosso, trad. livre).}

Distante de um possível uso depreciativo, ser "primitivo" assume para Simondon uma conotação positiva, pois liga diretamente o desenvolvimento técnico ao desejo e à intuição. É da invenção que está falando Simondon, do processo criativo, independente da apropriação econômica, mesmo sem ignorá-la. Nesse sentido, pode existir desenvolvimento tecnológico e econômico sem que haja necessariamente melhoria social, o que vai de encontro às ideias e práticas de Fuller. Para Simondon trata-se sempre de analisar o sistema completo das atividades e da existência, na relação entre aquilo que o homem produz (suas concretizações objetivas) e o que o homem é em relação ao mundo e, mais ainda, ao próprio universo (FREIRE, 2012a). Curiosamente, os chamados "povos primitivos" (aqui se usa as aspas propositadamente, dado o uso vulgar que se faz do primitivo) funcionam dessa maneira, é como praticam o que chamamos de invenção, essencialmente ligada à tecnicidade, seguindo a lógica de seus ancestrais de 
que nem tudo que é inventado precisa ser necessariamente concretizado, ou seja, uma prática do processo de virtualização sofisticada e em relação direta com sua cosmologia.

De vários anos para cá, pelo menos a partir dos anos 90, se fala com maior ênfase e naturalidade mais em inovação tecnológica do que em invenção, sendo que tudo o que é possível ser feito tem necessariamente que ser realizado, seguindo muitas vezes uma lógica contrária àquela citada acima. Para além da mudança de nomenclatura, o que está em jogo é o que ela significa epistemologicamente. Como dissemos em outra oportunidade:

Na palavra inovação foi embutido todo um aparato: instituições para todos os tipos e gostos, das financeiras às educacionais, imbuídas de um só espírito, empreendedor, na missão solene de promover a inovação em forma de produção de patentes e uma espécie de aposta no controle sobre os incrementos próprios para a aceleração do processo de consumo tecnológico, ao mesmo tempo em que a invenção tornara-se apenas uma parte do processo, desejada e, muitas vezes, sufocada. É o modo que o capital encontrou de usar o processo inventivo para gerar mais valor, abstrato, sua especialidade desde sempre, já resumia Marx. (Freire, 2012a, p. 107).

O que Simondon e Buckminster-Fuller propõem, cada qual à sua maneira, é um deslocamento da produção tecnológica respeitando suas características mais essenciais, ou seja, centrando na invenção. Assim, se desviaria do mercado enquanto uma espécie de gestor do fazer tecnológico, já que este, por não conhecer nada tecnologia, fará sempre apenas um uso utilitário dela para gerar mais valor (Freire, 2012a). Ou seja, a integridade no fazer tecnológico e científico de que falava Buckminster Fuller é completamente obscurecida pela enunciação dos benefícios intrínsecos ao seu uso, resquícios do discurso do progresso técnico positivista, uma espécie de ativo privilegiado para facilitar a produção de valor exponencialmente. 
Esta é uma forma da cultura se defender da tecnologia, colocando o mercado como o mais capacitado para gerenciar os processos tecnológicos, subjugando-a ao fetiche da mercadoria tecnológica. Contrapor cultura e tecnologia é algo incoerente para Simondon, uma espécie de ressentimento em relação às técnicas. Ele dizia ainda que um uso puramente utilitário das técnicas pela cultura, como simples encadeamentos de meios, é próprio de um julgamento pré-industrial (Simondon, 2014), não faz mais sentido, ou pelo menos não deveria fazer, depois da Revolução Industrial com seus desdobramentos e, mais ainda, após o desenvolvimento da cibernética e da teoria da informação.

Entender o mecanismo que envolve o processo de feitura tecnológica é, de início, perceber que ele não passa somente por uma institucionalização dos meios e nem mesmo por uma questão de conscientização coletiva dos bons e maus usos de um dado artefato técnico. Não se trata de um tribunal de justiça em que se coloca a máquina ou o homem para serem julgados moralmente, num jogo de oposições infindáveis. Como dizia Nietzsche, já no título de seu conhecido livro, é preciso ir além do bem e do mal, para além do que é dado no dado, para se alcançar um espírito livre. Vejamos esse seu provocador aforismo:

Supondo que nada seja "dado" como real, exceto nosso mundo de desejos e paixões, e que não possamos descer ou subir a nenhuma outra "realidade", exceto à realidade de nossos impulsos - pois pensar é apenas a relação desse impulsos entre si - : não é lícito fazer a tentativa e colocar a questão de se isso que é dado não bastaria para compreender, a partir do que lhe é igual, também o chamado mundo mecânico (ou "material")? Quero dizer, não como uma ilusão, uma "aparência", uma "representação" (no sentido de Berkeley e Schopenhauer), mas como da mesma ordem de realidade que têm nossos afetos, na qual ainda esteja encerrado em poderosa unidade tudo o que então se ramifica e se configura no processo orgânico (e

Filosofia e Educação - ISSN 1984-9605

Volume 6, Número 3 - Outubro de 2014 
também se atenua e se debilita, como é razoável), como uma espécie de vida instintiva, em que todas as funções orgânicas, como autoregulação, assimilação, nutrição, eliminação, metabolismo, se acham sinteticamente ligadas umas às outras - como uma forma prévia da vida? (Nietzsche, 1992, p. 42).

Se retomarmos a citação de Simondon sobre o primitivo da técnica e considerarmos que ele a considerava absolutamente universalizável, pois aquilo que do homem ressoa nela é tão íntimo, tão primitivo, tão próximo à vida ela mesma, que todo homem o possui em si (Simondon, 1990), entenderemos o alcance das palavras de Nietzsche quando fala em forma prévia da vida, condensando o pensar a partir dos impulsos do mundo da afecção. Em outras palavras, não somente não faz sentido algum opor homem e máquina como o próprio pensar tecnológico não poderia se distanciar do mundo dos afetos, dos instintos, dos desejos. Não se trata, portanto, da representação, da ilusão, da aparência ou da consciência como motores propulsores do processo inventivo, mas do que é compartilhado entre homem e técnica em sua relação mais interior, de dentro, próxima aos sentidos, aos instintos, de um pensar em conjunção com ou nessa forma prévia de vida, cuja relação cósmica é direta.

No fundo, quando Buckminster-Fuller refere-se à integridade na invenção ele está se referindo a esse processo, inclusive salientando a necessidade do do-it-yourself e não abrindo mão do método intuitivo como base de trabalho. Assim, não é somente uma questão de manter discussões politicamente corretas com denúncias posteriores à criação de uma determinada tecnologia e sim de compreendê-la em sua gênese como assunto de sobrevivência, vital. Buck-Fuller percebeu em determinado momento que era melhor mudar o ambiente via tecnologia do que tentar mudar ou conscientizar as pessoas. Realmente, não se trata apenas da inserção de tecnologia enquanto produto final na vida das pessoas, mas do como essa tecnologia é criada, do como ela é gestada, do como se dá a 
resolução dos problemas em sua forma embrionária, considerando variáveis micro e macroscópicas. Mais profundamente, de como esses problemas podem ser trabalhados na formação das pessoas, inclusive, mas não só, educacional e formal, de tal forma que se busque a integridade de que ele fala. Esse é um aspecto político da relação homem-máquina que mereceria não ser negligenciado.

Simondon afirmava que o conjunto técnico não pode ser compreendido senão por intuição. É que o conhecimento por intuição não é a priori nem a posteriori, mas contemporâneo àquele que o experimenta, é um método genético, transdutivo. O plano estético também se dá dessa forma, nada é preconcebido como um programa, nem surgirá posteriormente, mesmo que, como lembra Deleuze e Guattari, "sua tomada de consciência se faça progressivamente e surja frequentemente depois" (Deleuze \& Guatarri, 1992, p.252). Se olharmos as artes, sejam as que tematizam ou as que se utilizam de tecnologias contemporâneas diretamente para se expressarem, inevitavelmente também encontrarão o problema da tecnicidade no processo inventivo, que cada vez mais deixa de ser somente técnico e torna-se técnico-estético (Freire, 2012b). A intuição que nas artes aparece como algo natural, como matéria-prima para sua produção, não é menos crucial no desenvolvimento tecnológico.

A escolha por Simondon e Buckminster-Fuller neste texto é devido à importância dada em seus pensamentos para a intuição-sensação-percepçãoinformação enquanto motor do processo inventivo, aquele preocupado com a realização das potencias homem-tecnologia para além de interesses estritos e utilitários imediatos, como os do mercado, mas pela busca de uma contribuição mais objetiva para o todo, ou como dizia Fuller, para cem por cento dos habitantes do planeta, uma ambição cada vez mais urgente. 
A seleção do par técnica e estética não é casual e reporta-se diretamente a essa insistência em falar de algo mais abrangente, dessa ambição urgente e comum a Simondon e Fuller, se é que se pode chamar de ambição uma questão que em última instância é de sobrevivência, ou na melhor das hipóteses, de qualidade para a existência.

Em um dos trechos mais intrigantes de seu livro Du mode d'existence des objets techniques (MEOT), a terceira parte, Simondon, em sua busca pelo entendimento da gênese da tecnicidade, elabora uma hipótese original e que ajuda-nos nessas especulações iniciais sobre uma formação tecnoestética.

A primeira associação que o filósofo faz é a da gênese com o devir. Ele afirma que o devir não é mera atualização de uma virtualidade, ou mesmo o resultado de um conflito entre realidades atuais. Por isso dissemos acima que, diferente de nossa cultura, os povos "primitivos" não parecem estabelecer uma relação direta entre o que pode ser feito com o que deve ser feito, o que não significa que o devir, entendido como invenção, não esteja sendo construído o tempo todo, numa relação intensa entre homem e mundo, na relação entre figura e fundo, para usar os termos do próprio filósofo. Existe gênese, diz Simondon, quando um sistema de realidade primitivamente supersaturada, rica em potenciais, se resolve por uma estruturação, ou seja, há o aparecimento de uma organização, de uma figuração do fundo, que servirá de base para um equilíbrio metaestável (Simondon, 1969, p. 155). Um sistema metaestável comporta tensão e tendências, funciona por ressonância interna e é capaz ainda de receber novas informações, outras invenções, diferentemente de um sistema estritamente estável.

É interessante que em outro ponto, quando Simondon discorre especificamente sobre o problema educacional, ele colocará justamente a metaestabilidade no centro da discussão, pois em sua visão a industrialização do século XIX conduziu a uma sociedade estável e, agora, 
com o desenvolvimento industrial do século XX e da cibernética, estaríamos em um outro momento, em uma sociedade metaestável. Portanto, um desafio para a educação estaria em não somente preparar um especialista para um sociedade estável, mas para uma sociedade metaestável, o que significa para Simondon (2004, p. 237) prover uma "aprendizagem inteligente permitindo-lhe inventar", para resolver os problemas que se apresentarão, ou seja, estar atento às informações que emergem, às tendências do sistema. Uma verdadeira aprendizagem para Simondon, portanto, está relacionada à informação, à capacidade de adquirir numerosos esquemas integrados durante o processo de formação, “dando ao ser humano adulto um poder de plasticidade e de permanente adaptação inventiva" (Simondon, 2004, p. 240, trad. livre). Embora Simondon use ainda neste texto de 1954 a palavra adaptação, não é no sentido evolucionista habitual, de uma busca por um estado de equilíbrio cada vez mais estável, mas, ao contrário, objetiva-se o equilíbrio metaestável, pois é uma adaptação inventiva. Posteriormente, ele proporá a substituição da noção de adaptação pela de individuação, "concebida como resoluções sucessivas de tensões por descobertas de estruturas dentro de um sistema rico em potenciais" (Simondon, 1969, p.155, trad. livre). É onde encontramse as tendências, um feixe de sentidos apontando para devires outros e que possibilita uma análise genética. $\mathrm{O}$ devir se mostra enquanto individuações sucessivas de um sistema, individuação como invenção.

Todavia, para entender a existência dos objetos técnicos e sua importância na relação com o homem, incluindo os seus devires potenciais, Simondon considera pouco se perguntar somente sobre o sentido de sua gênese enquanto objetos já formados dentro da história do homem. Não basta apenas aprender os usos, benéficos ou não, de determinados objetos em um dado período do tempo, ainda que sejam os mais primitivos. Há um caminho mais vasto a ser percorrido. É sobre a própria gênese da tecnicidade que se deve perguntar, tanto dos objetos eles mesmos quanto

Filosofia e Educação - ISSN 1984-9605

Volume 6, Número 3 - Outubro de 2014 
das realidades não objetivadas, mas sempre a partir da experiência do homem sobre e com a terra, de sua individuação em relação ao meio.

Nesse ponto, a hipótese levantada por Simondon é de que a gênese da tecnicidade acontece ainda em um modo de existência pré-técnico e préreligioso, em uma primeira fase que ele denomina fase mágica. A noção de fase em Simondon está ligada a um desdobramento do ser, do aspecto resultante de uma mudança, como na física, e não como um momento temporal específico. Também, não se trata de dialética, uma fase não funciona por oposição a outras fases, nem o negativo aparece (Simondon, 1969). A fase mágica é a mais primordial, não por ser desprovida de qualquer organização, mas por conter os potenciais mais diretos e intensos do vivente em relação ao meio, isto é, por permitir a estruturação mais elementar de todas, "aquela que faz surgir a distinção entre figura e fundo no universo" (Simondon, 1969, p. 156).

A tecnicidade aparece enquanto processo de resolução de problemas entre o vivente e seu meio, ela surge para resolver uma incompatibilidade do sistema homem-mundo. Ao fazer esse papel, há uma defasagem do mundo mágico, que se desdobra em técnica e religião, a primeira especializando funções figurais e a segunda especializando funções de fundo. Há, portanto, um duplo movimento acontecendo: uma gênese $d a$ tecnicidade e uma gênese a partir da tecnicidade. $\mathrm{O}$ fato de haver ruptura com o mundo mágico não significa oposição entre religião e técnica, mas que duas tendências em tensão sofreram uma espécie de resolução, seguindo desdobramentos diferentes e, ao mesmo tempo, guardando relações ainda a serem exploradas com a totalidade:

Assim supersaturada, a tecnicidade se desdobra em teoria e prática, do mesmo modo que a religiosidade se separa em ética e em dogma. [...] a partir da tecnicidade, pelo desdobramento da tecnicidade original em figura e fundo, o fundo correspondendo às funções de totalidade independentes de cada aplicação dos gestos técnicos, enquanto a

Filosofia e Educação - ISSN 1984-9605

Volume 6, Número 3 - Outubro de 2014 
figura, feita de esquemas definidos e particulares, especifica cada técnica como maneira de agir. A realidade de fundo das técnicas constitui o saber teórico, enquanto os esquemas particulares provêm a prática (Simondon, 1969, p.158, trad. livre).

Se a gênese da tecnicidade e, a partir dela, o seu desdobramento na fase mágica em técnica e religião nos interessa aqui é porque Simondon considera que há um ponto neutro entre essas duas fases, um ponto de equilíbrio metaestável importante. É nesse ponto neutro que nasce o pensamento estético, que não é uma outra fase, mas funciona como uma espécie de lembrança permanente desse desdobramento, dessa ruptura com o mundo mágico. O pensamento estético traz como um análogo da fase mágica, se comporta como um mediador entre pensamento técnico e religioso, porém sendo mais primitivo que a ciência e a ética, pois estas precisaram de um desdobramento anterior (p. 160). A estética, assim, está mais próxima do mundo mágico e de sua ebulição de tendências original. Estar próxima não é o mesmo que pertencer à fase mágica e, também, não é sua representação, nem mesmo é o caso de nostalgia. Se for assim, se uma obra de arte, por exemplo, trabalhar nesses termos, sem dar o equivalente do mundo mágico por estar preocupada apenas com sua representação, pouco ou nada de contribuição ela trará para o conhecimento. De certa forma, como diz Simondon, o pensamento estético prolonga a existência da magia sem, no entanto, ser parte constituinte dela, uma vez que houve já a ruptura, não há como voltar, basta lembrar de $A$ morte de Empédocles, de Hölderlin, para citar um exemplo. Sua força é manter a função de totalidade. Trazer o equivalente não é o mesmo que representação. Já que não pode reconstruir o mundo mágico, o pensamento estético funciona como análogo, o primeiro análogo daquele mundo, e busca por uma unidade futura. Ou seja, memória e futuro num mesmo movimento inventivo, poder antecipatório.

É interessante que o filósofo sugere que se o saber científico e a ética pudessem ou conseguissem se unir, teríamos um segundo análogo, portanto, 
aproximando-se do mundo mágico e ainda mais completo. Nos tempos atuais, essa aproximação é usualmente discutida, mas nem sempre efetivamente atinge-se o nível de uma existência efetiva. Mais uma vez, a integridade de que fala Buck-Fuller passa por essas associações e aproximações. Tanto design quanto o desenvolvimento de tecnologias requerem uma proposição que passe pela estética e pela ética.

Nesse sentido, Simondon afirma que o pensamento estético, que se coloca no intervalo entre a subjetivação religiosa e a objetivação técnica (p. 182), conforma uma realidade estética intermediária, que não se encontra desligada do homem e do mundo. Como salienta Simondon:

ela [a realidade estética] pode permanecer atada ao mundo sendo, por exemplo, uma organização intencional de uma realidade natural; ela pode, também, continuar ligada ao homem, tornando-se uma modulação da voz, um aspecto de um discurso, uma maneira de se vestir. (Simondon, 1969, 183, trad. livre).

Em outras palavras: criação de uma perspectiva por modulação. Retorna-se aqui, como exemplo, ao filme de Perrin e Cluzaud: produção de perspectivas, incluindo alta tecnologia e o primitivo mar, sem desconsiderar as estrelas. Como dizia o texto do filme, o oceano é preciso senti-lo, saboreá-lo, criar uma perspectiva, seja de uma iguana, de uma máquina, de um ser humano, ou, melhor ainda, uma perspectiva pelo conjunto, transindividual para usar uma noção simondoniana ${ }^{2}$. Trata-se de inventar uma perspectiva em que alta tecnologia não esteja em desconexão com a magia da vida, sem qualquer romantismo, em que não se possa fazer a observação de Perrin e Cluzaud, de que no "espaço de uma vida, enquanto a humanidade alcançava as estrelas, parece que toda a natureza entrou em desequilíbrio". Prestando atenção ao que Buckminster Fuller dizia sobre a situação atual, é o próprio planeta que propõe este desafio cosmológico, seja

\footnotetext{
${ }^{2}$ Sobre o transindividual ver principalmente Simondon (1989).
} 
para invenções técnicas propriamente ditas quanto para invenções sociais de modo mais abrangente.

Na construção de perspectivas, a questão da tecnicidade reaparece como fundamental, é o que persiste enquanto campo problemático, pois:

os objetos surgem em certo momento, mas a tecnicidade os precede e os ultrapassa; os objetos técnicos resultam de uma objetivação da tecnicidade; eles são produzidos por ela, mas a tecnicidade não se esgota nos objetos e não está inteira contida neles (Simondon, 1969, p. 163, trad. livre).

E para que a tecnicidade exerça sua capacidade, seu poder de gênese na relação do homem com o mundo, como sugere Simondon, ela exige um grau de imaginação técnica no nível dos esquemas, dos elementos, que deveriam ser incorporados à formação, conforme sugerido anteriormente, para que ocorra a invenção:

A invenção [...] supõe no inventor o conhecimento intuitivo da tecnicidade dos elementos; a invenção se realiza neste nível intermediário entre o concreto e o abstrato, que é o nível dos esquemas, [...] fazendo parte de uma sistemática e de uma dinâmica imaginativas (Simondon, 1969, p. 73, trad. livre).

E sobre a imaginação, dirá Simondon:

A imaginação [...] é também capacidade de perceber em certos objetos qualidades que não são práticas, que não são nem diretamente sensoriais nem inteiramente geométricas, que não se reportam nem à pura matéria nem à pura forma, mas que estão nesse nível intermediário dos esquemas. Podemos considerar a imaginação técnica como definida por uma sensibilidade particular à tecnicidade dos elementos; é esta sensibilidade à tecnicidade particular que 
permite a descoberta de agenciamentos possiveis. [...] o individuo técnico deve ser imaginado (Simondon, 1969, pp. 73-74, itálicos nossos, trad. livre).

Nessas duas últimas frases Simondon sintoniza intuição, imaginação, percepção e sensação, no movimento da invenção. Mais de uma vez em seus escritos, Simondon manifesta que uma teoria da individuação deve se desenvolver em teoria da sensação, da percepção, da afecção, da emoção (Simondon, 1989, p. 274). Considerando esses elementos como fundamentais para o processo inventivo e que a técnica está associada ao primitivo, pois surge na fase mágica, enquanto a realidade estética, por sua vez, pode proporcionar um análogo dessa fase por modulação da relação homem-mundo, não por imitação ou representação, mas pela forma como o objeto estético se insere, por sua sensibilidade, compreende-se o porquê de Simondon se interessar mais detidamente por uma transição contínua que há entre objeto técnico e objeto estético, já que para ele existem objetos técnicos que têm um valor estético e que podem ser tidos como belos, pois:

todo objeto estético, móvel ou fixo, pode ter sua epifania estética, na medida em que ele prolonga o mundo e se insere nele. Mas, não é somente o objeto técnico que é belo: é o ponto singular do mundo que concretiza o objeto técnico. [...] ali reside uma operação muda, silenciosa, e sempre contínua da tecnicidade que se aplica ao mundo (Simondon, 1969, p. 185).

O filósofo desloca a questão da beleza contemplativa para a beleza da invenção, aumentando sua potencialidade numa relação tecno-estética. Não se trata da técnica somada a estética, mas do hífen que aparece entre elas, 
nesse ponto singular de encontro, metasestável, onde trabalha a tecnicidade. É uma fusão intercategórica, como definia o próprio Simondon.

Os leitores do filósofo conhecem bem uma carta dele endereçada a Derrida, publicada exatamente com o título Sobre a tecno-estética: Carta a Jacques Derrida. Nela, Simondon escreve ao amigo a propósito de um circular que havia recebido e que se era o caso de regenerar a filosofia, então, as interfaces precisavam ser consideradas, incluindo o pensamento e a prática religiosa, mas também o pensamento estético. É quando o filósofo sugere a fundação ou axiomatização de uma tecno-estética. Essa noção de tecno-estética será desenvolvida no decorrer da carta, com uma série de exemplos, de Corbusier a Eiffel, passando por motores de carros, ferramentas, até à Gioconda.

O senso de observação e associação de Simondon são impressionantes nessa carta. Às vezes circulando entre construções novas em determinado local nas proximidades de Paris ele diz ser possível sentir uma alegria que é, ao mesmo tempo, técnica e estética. Alegria que não se limita à contemplação das formas, mas concentra-se no sentir da ação arquitetural entrando em relação ao meio no qual as construções se instalam. Outras vezes, o exemplo dirige-se a um tipo de alicate, a uma forja, ao aperto de uma porca. No uso, na ação, na fusão entre forma e função, é que ele considera estar uma das categorias principais para pensar o espectro que atravessa técnica e estética.

Enfeitar um objeto técnico, ou mesmo estético, sem que haja uma função condizente com o conjunto, somente para um suposto embelezamento ou imitação, para Simondon é uma mentira, seria como um sinal de falsificação da tecnicidade, faltou integridade na realização, para citar o termo de Buck-Fuller. Quando analisa uma caixa d'água escondida em colunas simuladas de um certo castelo, Simondon dispara: 
Mas percebe-se que se trata de uma caixa d'água, de construção bem recente, e que tenta passar por um resto de castelo. Esta mentira materializada não acrescenta realmente nada ao charme do lugar. Ela apenas manifesta até onde pode-se ir em termos de mimetismo arquitetural" (Simondon, 1998, p. 265).

Muitas vezes, essa falsificação por embelezamento no design se fará em favor apenas do consumo, do mercado. Pode-se entender o alcance dessa percepção de Simondon quando se pensa em termos da formação. Ele estava respondendo a carta em função da formação filosófica, mas poderíamos expandir para o todo. Até que ponto um modelo de ensino focado nas exigências do mercado apenas, sem compreender o papel da tecnicidade, não pode sufocar as potências da relação homem-tecnologia? O fato da estética entrar em relação direta com a técnica, compondo um conjunto promissor para a formação, não se dá, portanto, em função de melhorar a aparência de um objeto técnico. Por isso, Simondon faz a seguinte reflexão:

A estética não é única nem primeiramente a sensação do “consumidor" da obra de arte. É também, mais originalmente ainda, o feixe sensorial mais ou menos rico, do próprio artista: um certo contato com a matéria enquanto trabalhada. Sentimos uma afecção estética ao fazer uma solda, ou ao enfiar um parafuso (Simondon, 1998, p. 257).

Percebemos que entram em jogo a sensação e a afecção novamente, ou melhor, elas nunca saíram, são parte constituinte da tecnicidade, de seu poder de resolução que permite novas abordagens, novas perspectivas, enfim, promovem invenções ao atuarem na captação de tendências.

Simondon não restringe, dessa maneira, a uma única norma a relação entre estética e técnica, àquela da funcionalidade. Além da relação com o meio, com a natureza, já citada, outra categoria é o próprio desvio da 
funcionalidade que pode ser promissor, pois "existe em torno de cada produto uma margem de liberdade que permite utilizá-lo com finalidades não previstas. [...] a sensibilidade estética pode ser utilizada para construir uma máquina" (p. 261).

E depois, Simondon, encaminhando-se para o final da carta, conclui que: "o sentimento tecno-estético parece ser uma categoria mais primitiva que o próprio sentimento estético, ou o aspecto técnico considerado sob o ângulo estrito da funcionalidade, que é empobrecedor” (p. 265).

\section{$* * * * *$}

Especular sobre a tecno-estética no ensino, ou na formação entendida de modo mais abrangente, nos tempos atuais é compreender, como foi dito com Simondon, que não se trata de uma simples sobreposição de dois campos separados, técnica mais estética, mas partir do princípio da potência dessa relação no seu aspecto mais urgente, o das exigências contemporâneas para a vida no planeta. O acento primitivo que Simondon colocava no sentimento tecno-estético é fundamental para transferir a discussão do âmbito dos objetos tecnológicos acabados para o próprio processo em sua gênese. Deslocar da conscientização para a ação mais próxima do fazer tecnológico estrito, o que faz com que a educação se torne chave nesse processo.

Se a ênfase é no hífen da tecno-estética, por outro lado, é comum no ambiente educacional desviarmos para os polos, em prol da inter ou multidisciplinaridade via alguma normatização. Tomemos como exemplo as orientações do MEC para cursos chamados interdisciplinares e destaquemos apenas algumas que mais interessam aqui:

1. Formação acadêmica geral alicerçada em teorias, metodologias e práticas que fundamentam os processos de produção científica, tecnológica, artística, social e cultural; 
2. Formação baseada na interdisciplinaridade e no diálogo entre as áreas de conhecimento e os componentes curriculares;

3. Foco nas dinâmicas de inovação científica, tecnológica, artística, social e cultural, associadas ao caráter interdisciplinar dos desafios e avanços do conhecimento;

4. Vivência nas áreas artística, humanística, científica e tecnológica;

Ora, essas orientações são já um avanço e vão, de certa forma, ao encontro de uma formação tecno-estética. Ao se falar em interdisciplinaridade, muitas vezes, supõe-se uma prática consolidada pelo entrelaçamento de diversas disciplinas para se atingir um objetivo, quer seja a construção de um aparato tecnológico, de uma teoria ou de um produto acadêmico de qualquer natureza. Desse modo, se fossemos pensar nesses termos de interdisciplinaridade para a tecno-estética, teríamos de um lado disciplinas técnicas enquanto de outro lado, disciplinas com foco estéticos e humanísticos, uma separação já comprometedora pelo que se viu até aqui.

Apesar de certo consenso da interdisciplinaridade enquanto forma de construção de conhecimento mais condizente às necessidades atuais, a realidade de sua aplicabilidade é um tanto quanto cruel. Congregar várias disciplinas e buscar pontos de contato pode ser um início, mas insuficiente. O desafio da chamada interdisciplinaridade está em fazer com que as barreiras das disciplinas se quebrem ou sejam borradas pelo menos, que as ressonâncias aconteçam de tal forma que o resultado final seja $1+1=3$, sempre sinergia, uma matemática incorreta. Tarefa nada fácil.

No entanto, além da não implementação efetiva dessas orientações para a interdisciplinaridade, dada a dificuldade intrínseca, há dois problemas de base muito maiores e que a educação é chamada constantemente a propor alguma resposta. Primeiro: aceitando-se a tecno-estética para a formação conforme descrita aqui via Simondon, dividi-la em dois polos disciplinares não faz sentido, pois é na relação, no ponto metaestável do hífen que as 
invenções se encontram, aquelas que podem contribuir efetivamente para dar a resposta cosmológica de que falava Fuller. Segundo: cabe se perguntar o porquê de ainda se manter a categoria "disciplina" junto aos prefixos "inter", "multi", trans" (disciplinares). Desde Foucault sabe-se que as disciplinas, que as sociedades disciplinares, estão em crise, supersaturadas, e que passamos para um outro tipo de sociedade, metaestável.

Assim, tem-se a dimensão da problemática da implementação de uma formação tecno-estética de fato. A mudança pode ser mais radical do que se supõe, o que não é negativo, mas um sinal de que é hora de inventar. Nesse caso, como se trata de especulações iniciais, parece mais sensato estabelecer algumas diretrizes básicas para compreensão da tecno-estética, como tentouse durante esse texto, e procurarmos por algumas pistas iniciais.

Para encontra-las, mais uma vez ouvir um inventor experiente pode ajudar. Buckminster Fuller, por tudo o que foi dito anteriormente e considerando sua trajetória pessoal, elencou em seu livro o que ele chamou de "as autodisciplinas de Buckminster Fuller", evidentemente pensando no processo inventivo pautado pela sua concepção de integridade (que Simondon (1989), por exemplo, poderia bem chamar de respeito ao modo de existência do objeto técnico). Eis algumas delas, nas palavras do próprio Fuller:

Busquei reformar o ambiente, não os humanos. Determinei nunca tentar persuadir a humanidade para alterar seus costumes e pontos de vista (Fuller, 1981, p.125, trad. livre).

Procurei nunca "promover" ou "vender" qualquer de minhas ideias ou artefatos, ou pagar outras pessoas para fazê-lo. [...] Todo apoio dever ser espontaneamente gerado pela integração da evolução de minhas invenções com a evolução dos interesses humanos (Fuller, 1981, p. 126, trad. livre). 
Busquei desenvolver meus artefatos com amplas margens antecipatórias de tempo, de modo que eles pudessem estar prontos para serem usados pela sociedade quando elas descobrissem, através das emergências evolucionárias, que elas somente precisariam daquilo que eu havia desenvolvido (Fuller, 1981, p.126. trad. livre).

E, finalmente:

Procurei produzir somente baseado no do-it-yourself e com base na intuição (Fuller, 1981, p. 127. trad. livre).

Apresentar tais citações não objetiva lançar receitas para a criação de mentes como a de Buckminster Fuller, evidentemente. Elas valem como provocação e comprovação de como o processo inventivo não está ligado diretamente ao mercado em primeira instância, pois tem um funcionamento próprio, pautado na tecnicidade. Mais ainda, dá dicas interessantes de como proceder ao se buscar uma formação tecno-estética, como por exemplo: fazer prevalecer a intuição no do-it-yourself, pensar em antecipação, apresentar as mudanças do ambiente mais do que pensar em algum tipo de “conscientização coletiva politicamente correta", entre outras.

$\mathrm{O}$ foguete refletido nos olhos da iguana, enquanto o límulo cruza lentamente a tela no filme de Perrin e Cluzaud, pode ser outra pista muito interessante.

\section{Referências bibliográficas}

BERGSON, Henri. Oeuvres. 5 ed. Paris: PUF, 1991.

COMBES, Muriel. Simondon: Individu et Collectivité. Paris: PUF, 1999.

DELEUZE, Gilles e GUATTARI, Félix. O que é a Filosofia? São Paulo: Editora 34, 1992.

FREIRE, Emerson. 'Tecnólogo e Mercado: uma relação a ser revisitada', In ALMEIDA, IVANETE B. P. \& BATISTA, Sueli S. S. (orgs.). Educação

\begin{tabular}{c}
\hline \hline Filosofia e Educação - ISSN 1984-9605 \\
Volume 6, Número 3 - Outubro de 2014
\end{tabular}


Tecnológica: reflexões, teorias e práticas, Jundiaí: Paco Editorial, 2012a.

. Da sensação ausente à sensação como potência: tema e variações sobre a relação arte-tecnologia. Tese de Doutorada defendida em cotutela entre UNICAMP e Universidade de Paris 1 - Panthéon Sorbonne, 2012b.

FULLER, Richard Buckminster. Critical Path. New York: St. Martin's Press, 1981.

. Manuel d'instruction pour le vaissean spatial "Terre". Baden/Suisse: Lars Müller Publishers, 1980.

HÖLDERLIN, F. A morte de Empédocles. São Paulo: Iluminuras, 2008.

KOPENAWA, Davi, and Bruce ALBERT. La chute du ciel: paroles d'un chaman Yanomami. Paris: Plon, 2010.

MARX, Karl. O capital: crítica da economia política. Rio de Janeiro: Civilização brasileira, 1980.

MARX, Karl. \& ENGELS, F. A ideologia alemã. São Paulo: Martins Fontes, 2001.

NIETZCHE, Friedrich. Além do Bem e do Mal: prelúdio para uma filosofia do futuro.

São Paulo: Companhia das Letras, 1992.

SENRA, Stella. "Conversações em Watoriki: das passagens de imagens às imagens de passagem: captando o audiovisual do xamanismo". In: Cadernos de Subjetividade 13, no. outubro 2011, 55-77.

SIMONDON, Gilbert. L'individu et sa genèse physico-biologique: l'individuation à la lumière des notions de forme et d'information. Paris: Press Universitaires de France, 1964.

Du mode d'existence des objets techniques. Paris: Aubier - Montaigne, 1969.

L'individuation psychique et collective: à la lumière des notion de forme, information, potentiel et métastabilité. Paris: Aubier, 1989.

. "Les Limites Du Progrès Humain". In: Cabiers Philosophiques, Centre National de Documentation Pédagogique, no. 42, 1990: 7-14.

. "Sobre a Tecno-Estética: Carta a Jacques Derrida." In: ARAÚJO, H.

R., Tecnociência e Cultura. São Paulo: Estação Liberdade, 1998.

Cours sur la perception (1964-1965). Chatou - France: Les Éditions de La 
Transparence, 2006.

Imagination et Invention (1965-1966). Chatou: Les Éditions de La

Transparence, 2008.

. Sur la Technique (1953-1983). Paris: Presses Universitaires de France, 2014.

WIENER, Norbert. Cibernética e Sociedade: o uso bumano de seres humanos. São Paulo: Cultrix, 1968. 